\title{
Application of a High Chromium Steel to Roughing Work Rolls for Hot Strip Mills
}

\author{
Hisashi HIRAOKA, Yoshihiro KATAOKA, ${ }^{1)}$ Kouji YUDA, ${ }^{2)}$ Kazuyuki TANIGUCHI, Mikio SASADA \\ and Itaru HISHINUMA ${ }^{3)}$
}

Iron \& Steel Research Laboratories, Kawasaki Steel Corporation, Kawasaki-cho, Chuo-ku, Chiba, Chiba-ken, 260 Japan.

1) Iron \& Steel Research Laboratories, Kawasaki Steel Corporation, Kawasaki-cho, Handa, Aichi-ken, 475 Japan.

2) Chita Works, Kawasaki Steel Corporation, Kawasaki-cho, Handa, Aichi-ken, 475 Japan.

3) Mizushima Works, Kawasaki Steel Corporation, Kawasaki-dori, Mizushima, Kurashiki, Okayama-ken, 712 Japan.

(Received on April 20, 1992; accepted in final form on July 17, 1992)

\begin{abstract}
High-chromium ( $\mathrm{Hi}-\mathrm{Cr}$ ) iron rolls have good wear resistance, but have certain disadvantages in their application to roughing mills. The influence of $\mathrm{C}$ and $\mathrm{Cr}$ contents on material and mechanical properties were examined.

The dendritic structure of the material changes with $\mathrm{C}$ and $\mathrm{Cr}$ contents, with the structure of lower $\mathrm{C}$ and $\mathrm{Cr}$ steel being larger than that of higher $\mathrm{C}$ and $\mathrm{Cr}$ iron. Hot hardness and wear resistance do not depend on $\mathrm{C}$ and $\mathrm{Cr}$ contents, while the mechanical wear of these materials decreases with increasing hardness. The thermal shock resistance decreases with decreasing $\mathrm{Cr}$ content.

Using $\mathrm{Hi}$ - $\mathrm{Cr}$ steel rolls instead of $\mathrm{Hi}-\mathrm{Cr}$ iron rolls in a hot strip roughing mill, accidental slippage was prevented by their rougher surface and better performance obtained by increasing hardness.
\end{abstract}

KEY WORDS: work roll; high chromium steel; high chromium iron; hot strip mill.

\section{Introduction}

Many materials for work rolls have been modified in hot strip mills to satisfy the requirements for better surface quality and reduced cost of hot-rolled sheet. High-chromium (Hi-Cr) iron rolls $(2.6-2.8 \% \mathrm{C}, 16-$ $18 \% \mathrm{Cr}$ ) were first applied to the former stands of finishing trains about ten years ago in Japan. This iron demonstrated strong resistance to wear and the surface deterioration of the work rolls, and rolls made of this material have been more widely used than conventional Adamite steel rolls. $\mathrm{Hi}-\mathrm{Cr}$ iron rolls have recently been applied to the second part of the stands in roughing mills. While wear resistance has doubled, the frequency of accidental slippage occurring between the work rolls and sheet has also increased. This may be due to the increasing hardness and carbide quantity of these iron rolls compared to Adamite steel rolls.

$\mathrm{Hi}-\mathrm{Cr}$ steel $(0.7-1.4 \% \mathrm{C}, 8-14 \% \mathrm{Cr})$ rolls have been used in the second part of roughing at the majority of hot strip mills in North America and Europe, and the advantage of these $\mathrm{Hi}-\mathrm{Cr}$ steel rolls have been reported. ${ }^{1-4)}$ However, the data concerning the properties of $\mathrm{Hi}-\mathrm{Cr}$ steel rolls were inadequate to prove their applicability to roughing mills. Even $\mathrm{Hi}-\mathrm{Cr}$ iron roll was not viewed as advantageous in Japan during the 1970 's when it was the major material used for former stands of finishing mills in Europe. The material of a work roll has to be selected according to the rolling conditions and mill configuration. Generally, the wear resistance of rolls are closely related with the volume fraction of carbide. The wear resistance of $\mathrm{Hi}-\mathrm{Cr}$ steel is uncertain, the volume fraction of carbide being less than that of $\mathrm{Hi}-\mathrm{Cr}$ iron.

Carbon and chromium are the most effective elements forming the carbide which contribute to the wear resistance of $\mathrm{Hi}-\mathrm{Cr}$ steel and iron rolls. Depending on the proportion of chromium content to carbon content, three types of carbides are formed: $\mathrm{M}_{3} \mathrm{C}, \mathrm{M}_{7} \mathrm{C}_{3}$ and $\mathrm{M}_{23} \mathrm{C}_{6}$. Carbides of the $\mathrm{M}_{7} \mathrm{C}_{3}$ type are considered the most preferable of these for rolls, and $\mathrm{Hi}-\mathrm{Cr}$ iron rolls with a chromium-carbon ratio of $7: 1$ have been applied to mills.

The influence of the carbon and chromium contents is examined, and the optimum chemical composition is proposed for roughing mills. The results of the application of $\mathrm{Hi}-\mathrm{Cr}$ steel rolls to a roughing mill are also discussed.

\section{Experimental Procedure}

\subsection{Materials}

The materials were melted in a high-frequency induction furnace and poured into sand molds, in which a chiller was set at the bottom. The weight of each ingot was about $20 \mathrm{~kg}$ and the shape was a "Y" block of $30 \mathrm{~mm}$ thickness.

Table 1 shows the chemical composition range of the 
Table 1. Chemical composition range of the specimens.

\begin{tabular}{lcccccccc} 
& $\mathrm{C}$ & $\mathrm{Si}$ & $\mathrm{Mn}$ & $\mathrm{P}$ & $\mathrm{S}$ & $\mathrm{Ni}$ & $\mathrm{Cr}$ & $\mathrm{Mo}$ \\
\hline Max. & 2.8 & 1.1 & 0.8 & 0.02 & 0.013 & 1.3 & 22.0 & 2.0 \\
Min. & 0.8 & 0.9 & 0.6 & 0.01 & 0.005 & 1.0 & 6.9 & 1.8 \\
\hline
\end{tabular}

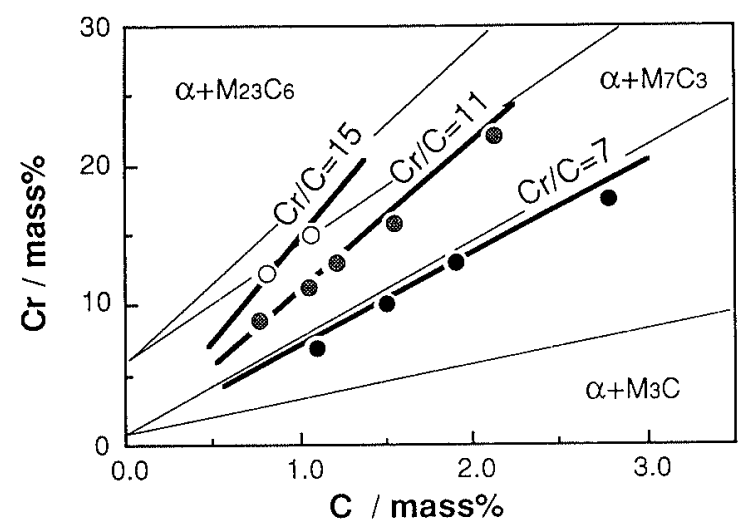

Fig. 1. $\mathrm{C}$ and $\mathrm{Cr}$ contents of specimens in the $\mathrm{Fe}-\mathrm{C}-\mathrm{Cr}$ phase diagram at room temperature. Compositions can be classified into three groups: $\mathrm{Cr} / \mathrm{C}=7,11$ and 15 .

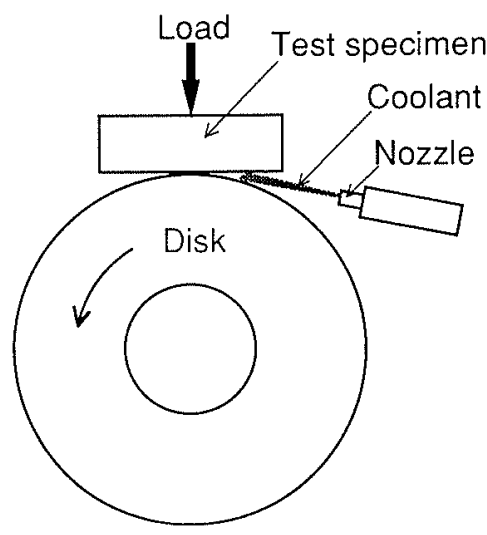

Fig. 2. Schematic diagram of the thermal shock testing apparatus.

$\mathrm{Hi}-\mathrm{Cr}$ iron and steel used, while the contents of carbon and chromium are shown by a phase diagram in Fig. 1. The compositions of these materials can be classified into three groups by the chromium-carbon ratio: $\mathrm{Cr} / \mathrm{C}=7$, 11 and 15.

After heat-treating the ingots, test blocks were cut out at a position which is $30 \mathrm{~mm}$ from the chiller for microscopic observation.

\subsection{Mechanical Properties}

A hot hardness test, wear test and thermal shock test were conducted. The test specimen for hot hardness was $35 \times 35 \times 35 \mathrm{~mm}^{3}$. Rockwell hardness $\mathrm{HRC}$ was measured from room temperature to $1023 \mathrm{~K}$ with the increment of 50 or $100 \mathrm{~K}$.

The wear was measured with an Ohgoshi wear testing machine (modified Spindel ${ }^{5)}$ type) without lubrication. Specimens were $50 \times 20 \times 10 \mathrm{~mm}^{3}$, and the rotary disk in a tool steel was $30 \mathrm{~mm}$ in diameter and $3 \mathrm{~mm}$ in thickness. The slipping rate was from 0.1 to $4.3 \mathrm{~m} / \mathrm{s}$, and slipping distance and final load were $600 \mathrm{~m}$ and $130 \mathrm{~N}$, re-

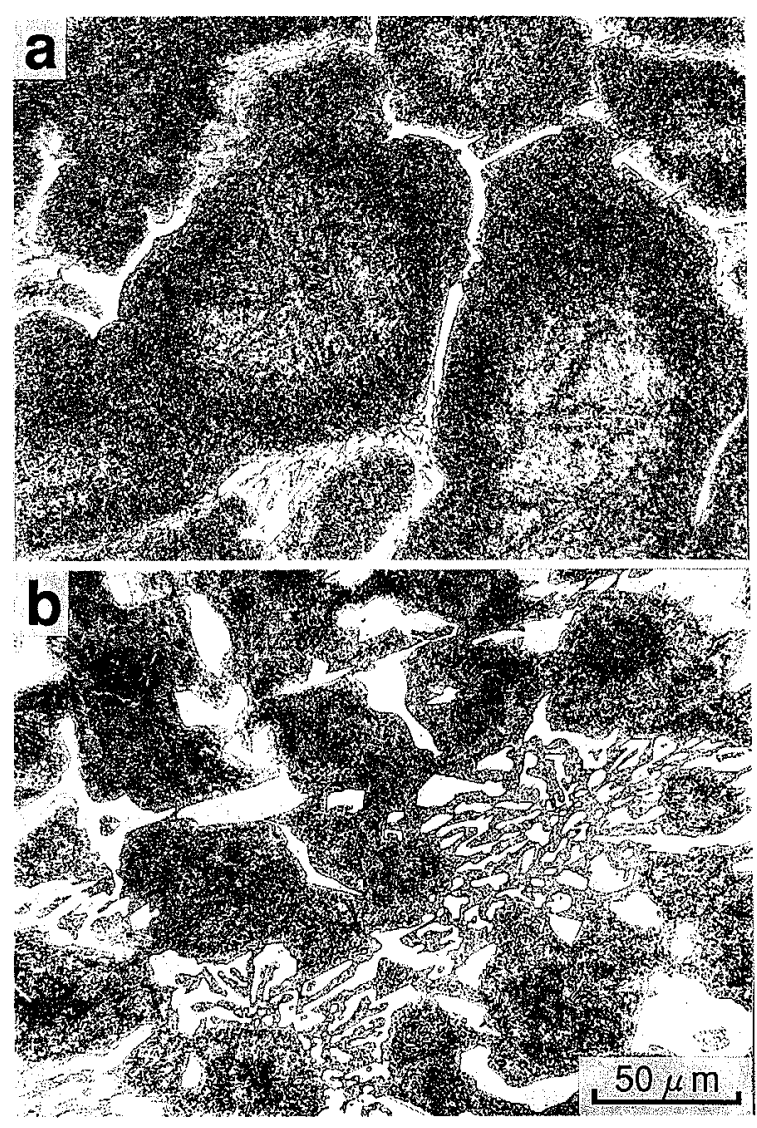
(a) $1.0 \% \mathrm{C}-11 \% \mathrm{Cr}$
(Hi-Cr steel)
(b) $2.7 \% \mathrm{C}-18 \% \mathrm{Cr}$
(Hi-Criron)

Fig. 3. Optical microstructures of typical $\mathrm{Hi}-\mathrm{Cr}$ iron and steel.

spectively.

Figure 2 shows a schematic diagram of the thermal shock testing machine. ${ }^{6)}$ The size of each specimen is $55 \times 40 \times 15 \mathrm{~mm}^{3}$ and the rotary disk made of tool steel is $350 \mathrm{~mm}$ in diameter and $30 \mathrm{~mm}$ in thickness. Each specimen was pressed on the rotary disk under a load of $1500 \mathrm{~N}$ for $15 \mathrm{sec}$. The contact face was then quenched by water immediately after the specimen was separated from the rotary disk, and several cracks were induced by the thermal shock. After tests each specimen was cut parallel to the slipping direction at the widest crack, and the depth and interval of cracking were measured in the cross section.

\section{Results and Discussion}

\subsection{Microstructure and Dendritic Structure}

The volume fraction of eutectic carbide decreases with decreasing carbon and chromium contents. Figure 3 shows typical examples of the microstructure of $\mathrm{Hi}$ $\mathrm{Cr}$ iron $(2.6 \% \mathrm{C}, 18 \% \mathrm{Cr})$ and steel $(1 \% \mathrm{C}, 11 \% \mathrm{Cr})$, eutectic carbide appearing as white rods or particles in the micrographs. The volume fractions of eutectic carbide in the $\mathrm{Hi}-\mathrm{Cr}$ steel and iron are 5 and $25 \%$, respectively, and the dendritic structure becomes larger with decreasing carbon and chromium. Figure 4 shows examples of the dendritic structure observed in a composition series with a chromium-carbon ratio of seven. 


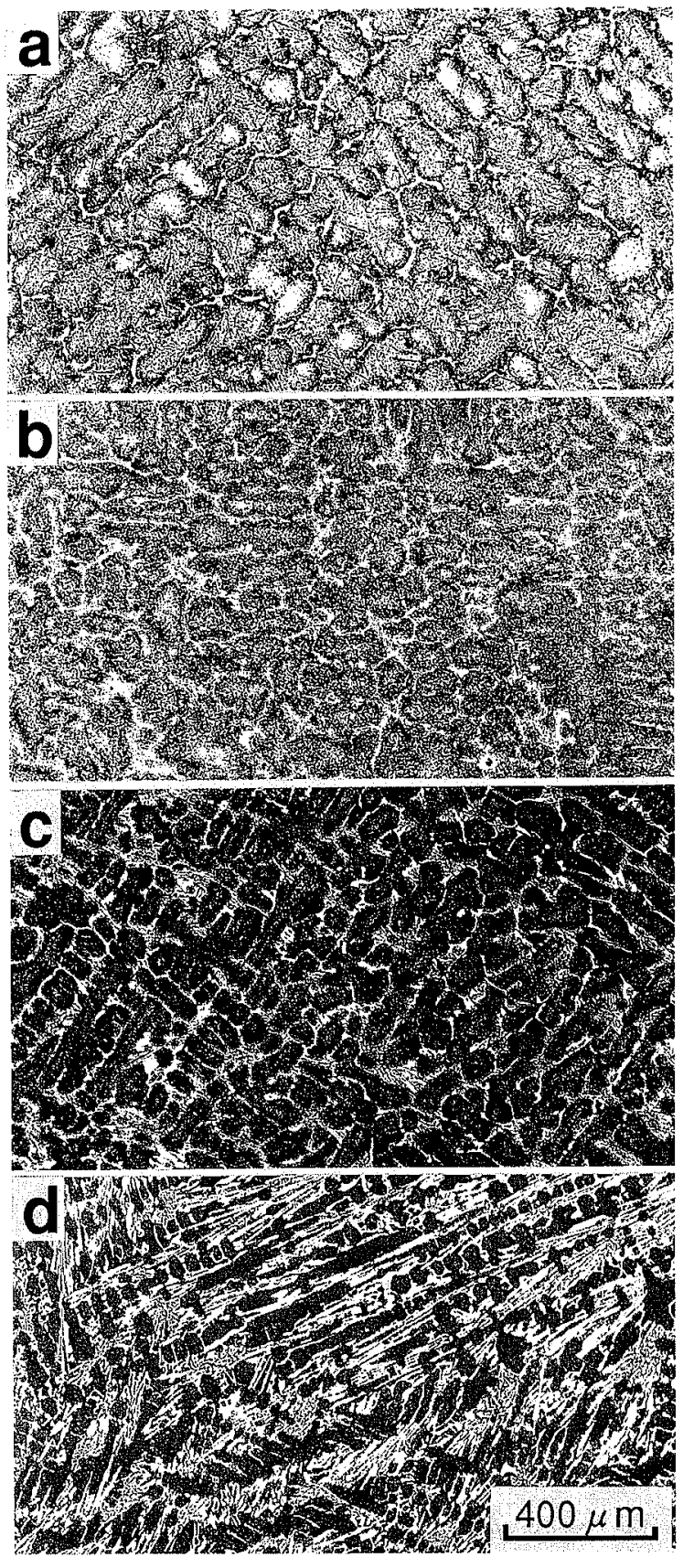
(a) $1.1 \% \mathrm{C}-7 \% \mathrm{Cr}$
(b) $1.5 \% \mathrm{C}-10 \% \mathrm{Cr}$
(c) $1.9 \% \mathrm{C}-13 \% \mathrm{Cr}$
(d) $2.8 \% \mathrm{C}-18 \% \mathrm{Cr}$

Fig. 4. Effects of $\mathrm{C}$ and $\mathrm{Cr}$ contents on the dendritic structures for a $\mathrm{Cr} / \mathrm{C}$ ratio of 7 .

While secondary dendrite arm spacing $\left(d_{2}\right)$ had a strong correlation with the contents of carbon and chromium, parameter $L$ indicated stronger correlation with $d_{2}$ than the multiple correlation of carbon and chromium. Parameter $L$ is defined by the carbon and chromium contents as Eq. (1) and represents the fraction of eutectic area in the microstructure.

$$
L=15.5 \times \% \mathrm{C}+\% \mathrm{Cr}
$$

The secondary arm spacing was inversely proportional to $L$ as shown in Fig. $5, L$ decreasing as $d_{2}$ increases. With decreasing carbon and chromium contents, $d_{2}$ increases. For instance, the dendrite arm spacing of $\mathrm{Hi}-\mathrm{Cr}$ steel $(1 \% \mathrm{C}, 11 \% \mathrm{Cr})$ was about twice larger than that

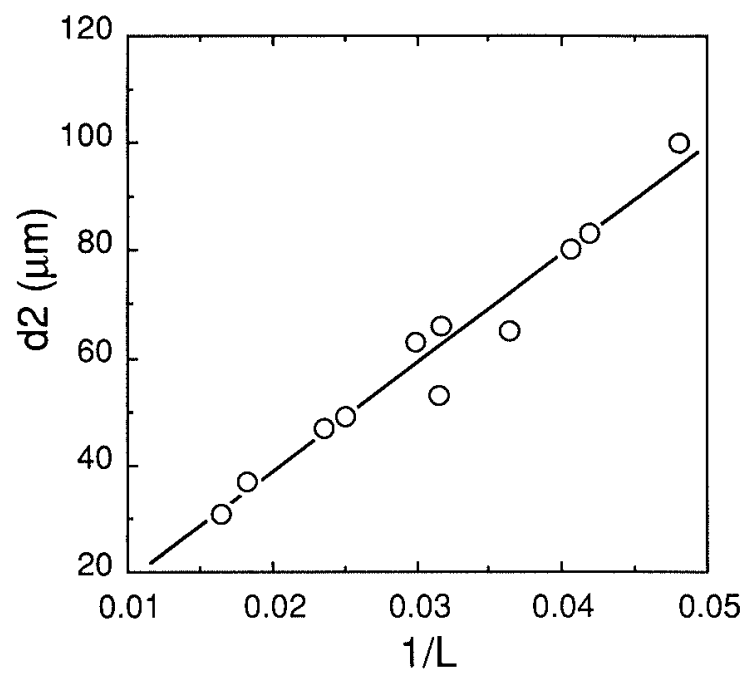

Fig. 5. Relationship between $d_{2}$ and parameter $L$. $d_{2}$ was measured from the micrographs.

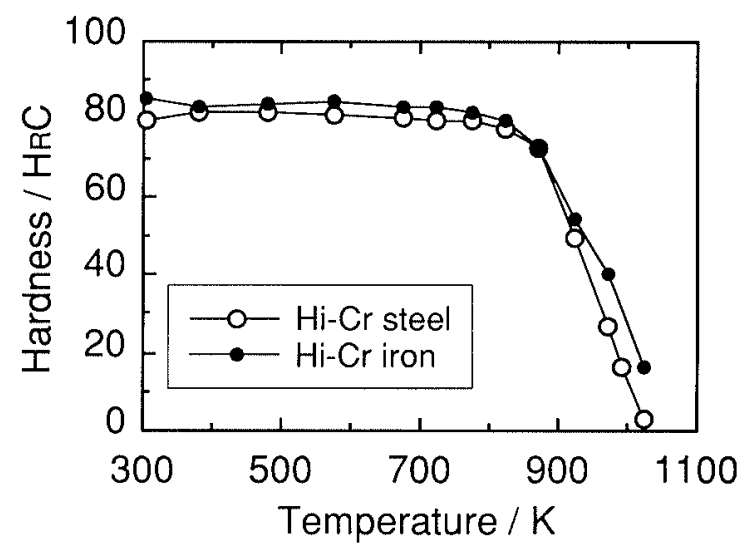

Fig. 6. Hot hardness at elevated temperature. The material compositions were $1.0 \% \mathrm{C}-10 \% \mathrm{Cr}(\mathrm{Hi}-\mathrm{Cr}$ steel) and $2.7 \% \mathrm{C}-18 \% \mathrm{Cr}$ ( $\mathrm{Hi}-\mathrm{Cr}$ iron).
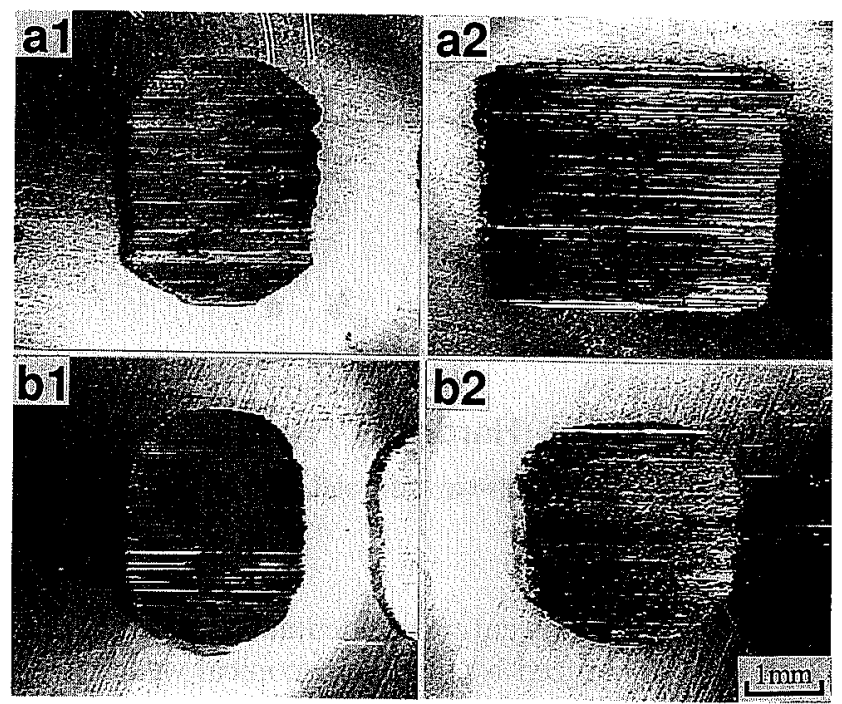

(a) $1.0 \% \mathrm{C}-11 \% \mathrm{Cr}$

(b) $2.7 \% \mathrm{C}-18 \% \mathrm{Cr}$

(1) slip rate $=0.3 \mathrm{~m} / \mathrm{s}$

(2) slip rate $=4.3 \mathrm{~m} / \mathrm{s}$

Fig. 7. Examples of indentations observed after the wear test.

of $\mathrm{Hi}-\mathrm{Cr}$ iron $(2.7 \% \mathrm{C}, 18 \% \mathrm{Cr})$. Microscopical wear is more marked in the primary crystal area than in the eutectic area, and a large dendritic structure may be 


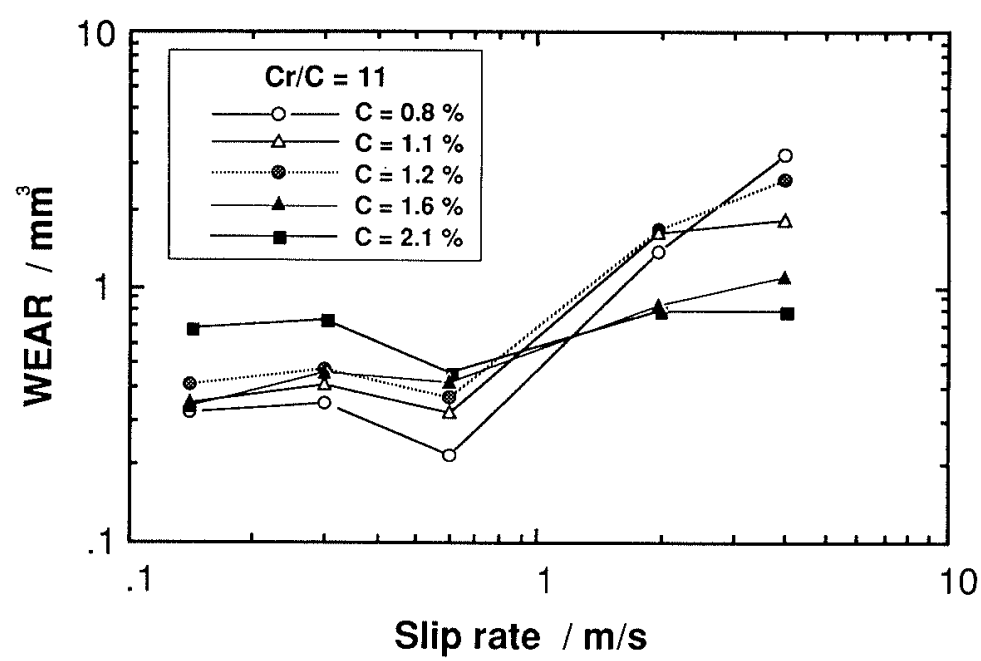

Fig. 8.

Relationship between wear and slip rate. $\mathrm{Cr} / \mathrm{C}$ ratio is 11 .

Slip rate $/ \mathrm{m} / \mathrm{s}$

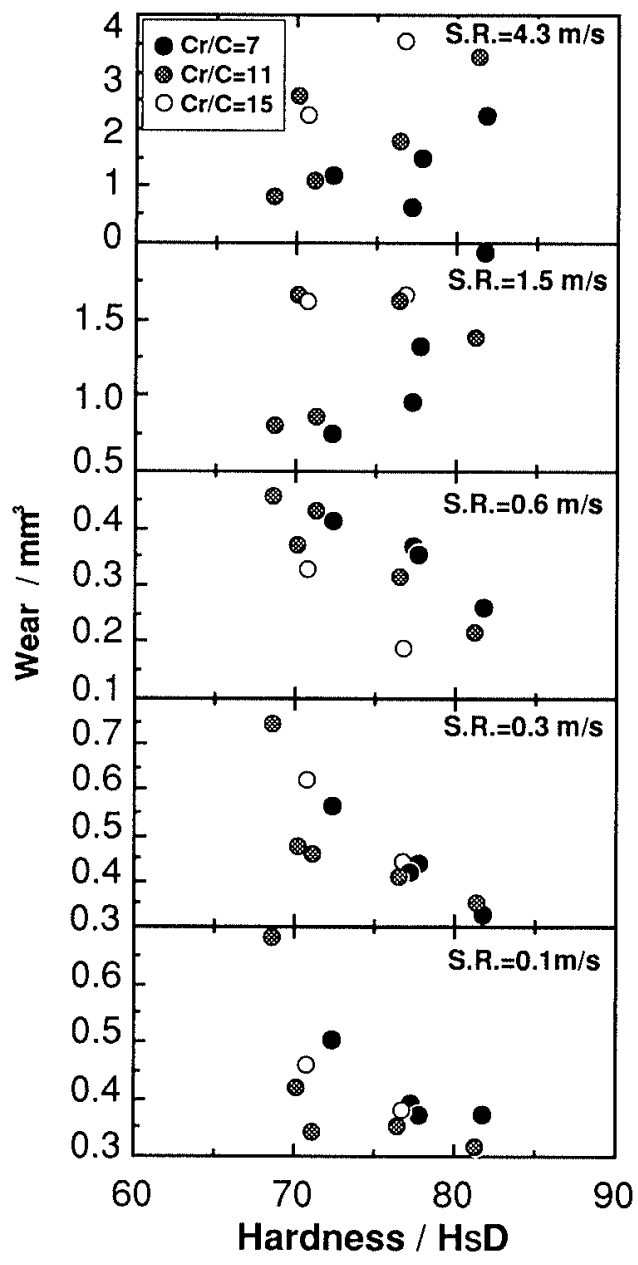

Fig. 9. Relationship between wear and hardness for several slip rates $(S . R$.

advantageous for preventing accidental slippage with its rough surface induced by the microscopical wear.

\subsection{Hot Hardness}

The hot hardness behavior of each material examined was nearly the same; typical examples of the hardness after heating from room temperature are shown in Fig. 6. Hot hardness can be seen nearly constant up to $673 \mathrm{~K}$, with softening of the material beginning at about $773 \mathrm{~K}$. Above $873 \mathrm{~K}$, the hot hardness decreases linearly with

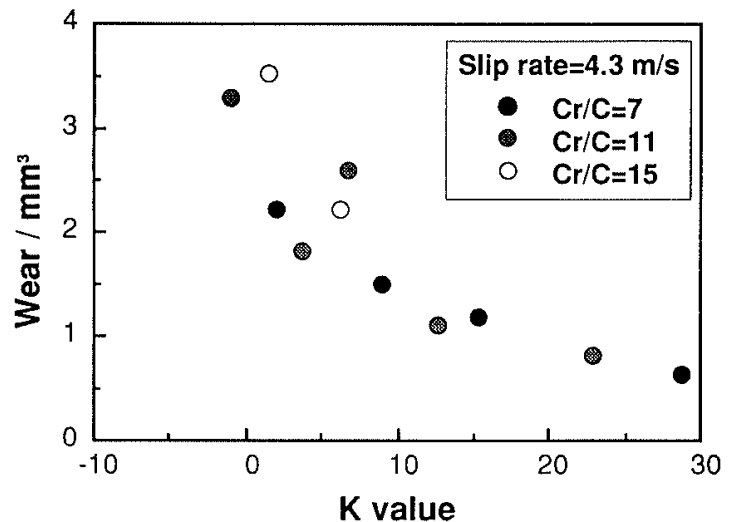

Fig. 10. Effect of parameter $K$ (estimated volume fraction of carbide) on the wear at a high slip rate of $4.3 \mathrm{~m} / \mathrm{s}$.

increasing temperature.

The hot hardness of rolls is an important factor for hot rolling. $\mathrm{Hi}-\mathrm{Cr}$ steel rolls seem to have the same characteristic softening as $\mathrm{Hi}-\mathrm{Cr}$ iron rolls, even though the microstructure of the two differs.

\subsection{Wear}

As shown in Fig. 7, features of the indentations created by the wear test vary with the test conditions, the wear in the Ohgoshi test being defined as volume of the indentations. Figure 8 shows the variation of wear with slip rate, where each plot represents the average of three wear data. The mechanism for wear was mechanical abrasion at low slip rates (e.g., 0.1 and $0.3 \mathrm{~m} / \mathrm{s})$. Wear decreased with the oxide film formed on the contact surface at a medium slip rate (e.g., $0.6 \mathrm{~m} / \mathrm{s})$, and became large with melting at higher slip rates (e.g., 1.5 and $4.3 \mathrm{~m} / \mathrm{s}$ ).

The relationship between wear and hardness is shown in Fig. 9; in general, the two are closely related. However, the wear had no correlation with hardness at a high slip rate, e.g., $4.3 \mathrm{~m} / \mathrm{s}$. After several examinations, the wear at a high slip rate correlated with the volume fraction of carbide $(K)$ as shown in Fig. 10, where the value for $K$ was calculated numerically from Eq. (2) as proposed by Maratray et al. ${ }^{\text {.) }}$

$$
K=12.3 \times \% \mathrm{C}+0.55 \times \% \mathrm{Cr}-15.2
$$




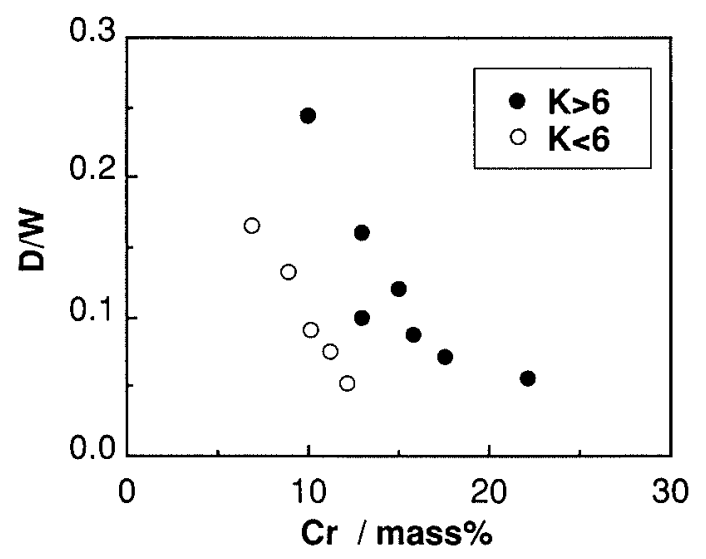

Fig. 11. Effect of $\mathrm{Cr}$ content on $D / W$, the ratio of the average depth and interval of cracks after the thermal shock test.

The wear decreased with increasing carbide volume fraction at high slip rates; i.e., under the condition of abrasion with melting.

On the other hand, the wear mechanism for a work roll during hot rolling is mechanical abrasion, so that the wear resistance of a $\mathrm{Hi}-\mathrm{Cr}$ steel roll does not depend on the volume fraction of carbide, being predictable from its hardness as shown in Fig. 9, while the volume fraction of carbide in $\mathrm{Hi}-\mathrm{Cr}$ steel is smaller than that in $\mathrm{Hi}-\mathrm{Cr}$ iron (Fig. 3). Materials with a $\mathrm{Cr} / \mathrm{C}$ ratio of 11 had good wear resistance (Fig. 9), except for the specimen with a high chromium content of $22 \%$.

\subsection{Thermal Shock Resistance}

Many short cracks induced by thermal shock were observed in the cross section of specimens. The depth of most cracks in each specimen was influenced by the contact area between the specimen and rotating disk, which depends on the hardness and the volume fraction of carbide. In this investigation, the thermal shock resistance was evaluated by the ratio of the average depth to the average interval of cracks $(D / W)$, which represents the material property for crack propagation. Figure 11 shows the influence of the chromium content on $D / W$. With increasing chromium content, the $D / W$ decreases, and a small carbide fraction is advantageous to decrease $D / W$ ( $K$ of less than 6 in Fig. 11).

It is apparent that the thermal shock is quite sensitive to the volume fraction of carbide, because carbide has low ductility. Furthermore, the influence of chromium content on the thermal shock resistance can be explained by its deformability at high temperature. The tensile strength at high temperature depends on the chromium content as shown in Fig. 12, and decreases with increasing chromium content at the relatively low temperature of $973 \mathrm{~K}$, which may be considered as the effect of strengthening with carbide distribution. At rather high temperature (especially at $1273 \mathrm{~K}$ ), however, the tensile strength becomes proportional to the chromium content.

Thermal shock resistance is one of the most essential factors for the mechanical properties of work rolls, because the deterioration of a roll surface is caused by small pits which are initated by cracks. In roughing mills, large cracks and pits which were induced by thermal

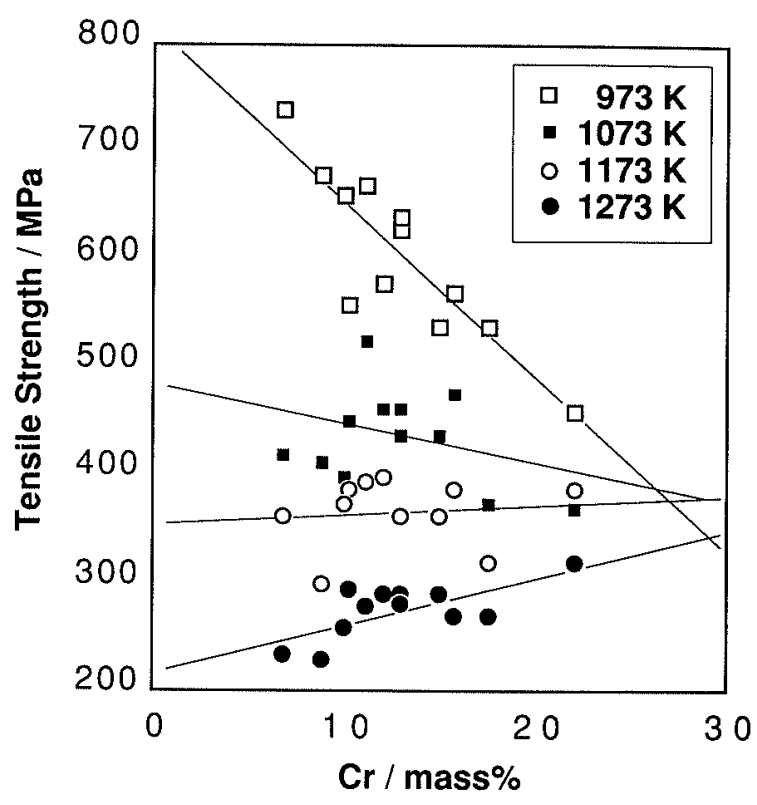

Fig. 12. Relationship between the $\mathrm{Cr}$ content and tensile strength at high temperatures of $973,1073,1173$ and $1273 \mathrm{~K}$.

shock were observed on the surface of an Adamite steel roll $(1.5-2 \% \mathrm{C}, 1-2 \% \mathrm{Cr})$, demonstrating the importance of examining the thermal shock resistance of $\mathrm{Hi}-\mathrm{Cr}$ steel rolls. High resistance to thermal shocks can be obtained with a high content of chromium. Compared with conventional $\mathrm{Hi}-\mathrm{Cr}$ iron $(2.7 \% \mathrm{C}, 18 \% \mathrm{Cr})$, similar or better resistance to thermal shock can be expected in $\mathrm{Hi}-\mathrm{Cr}$ steel, if the chromium content is kept above $10 \%$ (Fig. 11).

\section{Application of Hi-Cr Steel to Roughing Work Rolls}

$\mathrm{Hi}-\mathrm{Cr}$ steel rolls with $\mathrm{Hi}-\mathrm{Cr}$ steel shell and gray cast iron core were applied as a trial to the secondary stands (i.e., from the $3 \mathrm{rd}$ to 5 th stands) of the roughing mill in a hot strip mill, the chemical composition of $\mathrm{Hi}-\mathrm{Cr}$ steel being determined from the results of this investigation. Using $\mathrm{Hi}-\mathrm{Cr}$ steel rolls, the accidental slippage between the rolls and sheet was prevented, and the roll performance was better than that of $\mathrm{Hi}-\mathrm{Cr}$ iron rolls.

The surface deterioration of rolls becomes worse with increasing of the amount of rolling. Figure 13 shows typical examples of the features of roll surfaces which were observed at the 3rd stand after rolling $60000 \mathrm{t}$. While it is apparent that the Hi-Cr steel roll has a rougher surface than the $\mathrm{Hi}-\mathrm{Cr}$ iron, small pits can be seen on the Hi-Cr iron roll, as shown by the arrows in Fig. 13, whereas none were observed on the $\mathrm{Hi}-\mathrm{Cr}$ steel roll.

The roughness of the roll surface at the 5 th stand after rolling $40000 \mathrm{t}$ is shown in Fig. 14, where the direction of measurement was perpendicular to the rolling direction. In the Hi-Cr steel, large cyclic peaks can be seen. On the contrary, the surface of the $\mathrm{Hi}-\mathrm{Cr}$ iron is relatively smooth, the range between peak and trough being small. Stable rolling without slipping was produced by the rough surface of the $\mathrm{Hi}-\mathrm{Cr}$ steel roll, the average roughness $(R a)$ of the Hi-Cr steel roll being twice that of the $\mathrm{Hi}-\mathrm{Cr}$ iron roll. This difference may be related to 


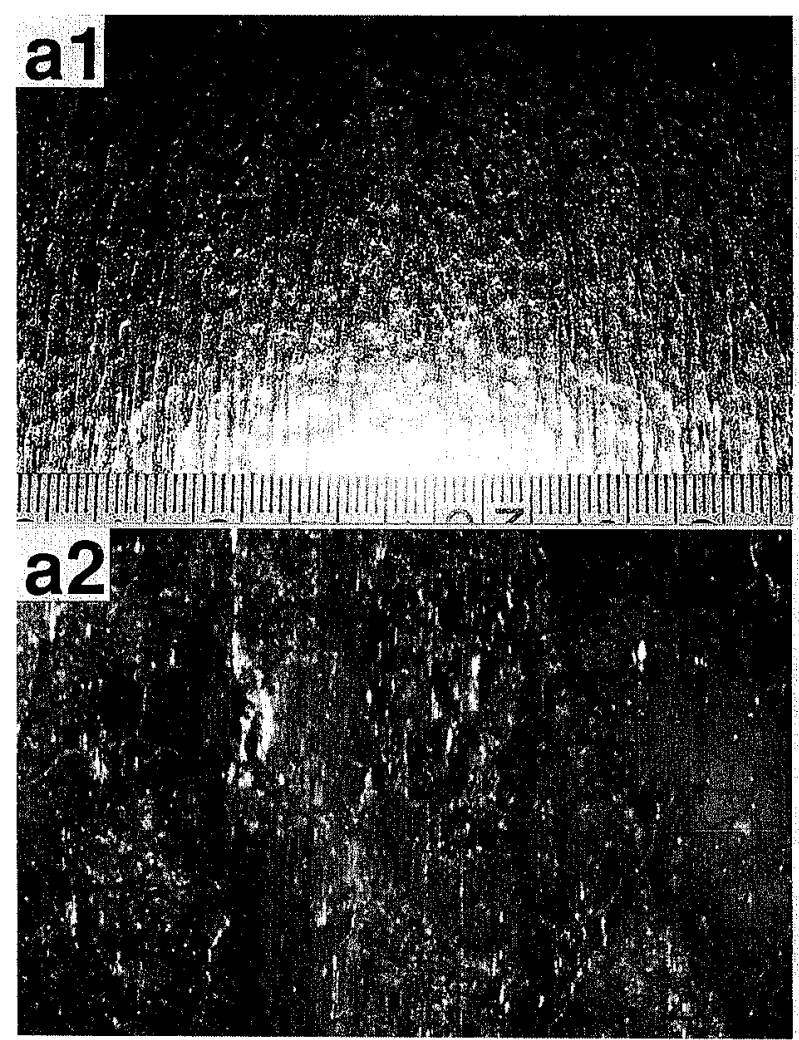

(a) $\mathrm{Hi}-\mathrm{Cr}$ steel roll
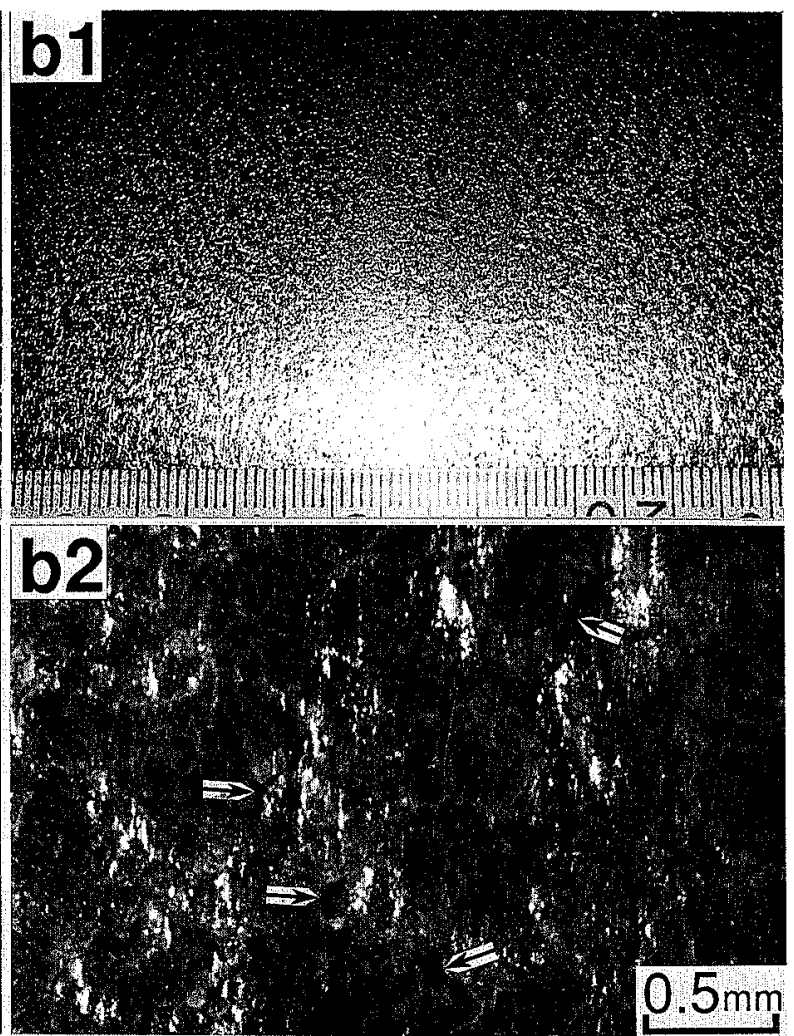

(b) Hi-Cr iron roll

Fig. 13. Typical examples of roll surface features observed at the 3 rd stand of a roughing mill after rolling about. $60000 \mathrm{t}$.
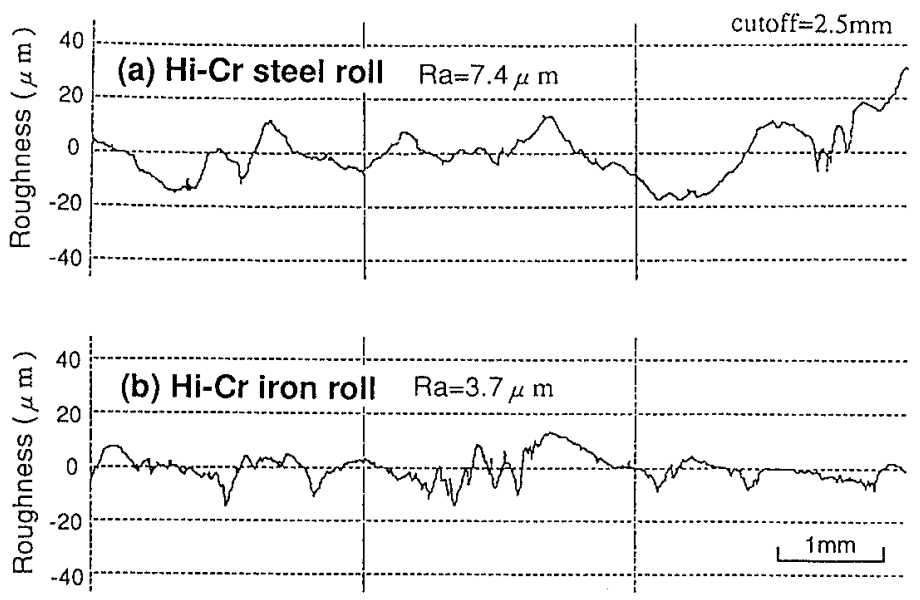

Fig. 14.

Examples of roll surface roughness observed at the 5 th stand of a roughing mill after rolling about $40000 \mathrm{t}$. Roughness was measured perpendicular to the rolling direction. (a) Hi-Cr steel roll

upper roll

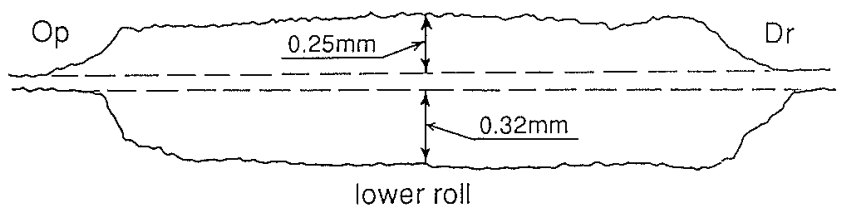

(b) Hi-Cr iron roll

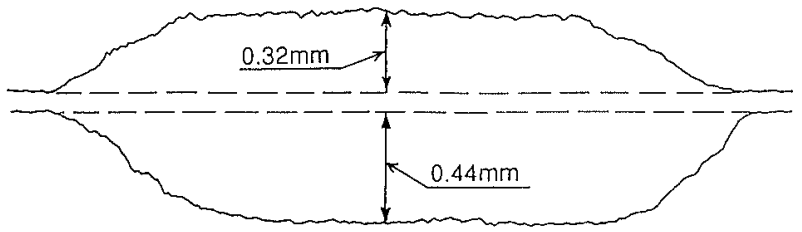

Fig. 15. Comparison of roll profile with roll material after long-term operation. These data were measured from the same rolls as those in Fig. 14. the dendritic structure, since the secondary arm spacing of $\mathrm{Hi}-\mathrm{Cr}$ steel was nearly twice that of $\mathrm{Hi}-\mathrm{Cr}$ iron.

In spite of its rough surface, the performance of the $\mathrm{Hi}-\mathrm{Cr}$ steel roll was better than that of the $\mathrm{Hi}-\mathrm{Cr}$ iron roll. Figure 15 shows roll wear profiles of the rolls in Fig. 14. In the case of the $\mathrm{Hi}-\mathrm{Cr}$ steel roll, the maximum wear depth was reduced from 0.32 to $0.25 \mathrm{~mm}$ on the upper roll, and from 0.44 to $0.32 \mathrm{~mm}$ on the lower roll.

This difference in roll performance was caused by the hardness of the rolls. The maximum hardness of the $\mathrm{Hi}-\mathrm{Cr}$ iron roll was $\mathrm{HsD} 70$ to prevent slippage. On the other hand, the hardness of the $\mathrm{Hi}-\mathrm{Cr}$ steel roll was about HsD 80, causing no slippage in normal operation. Consequently, the performance of the $\mathrm{Hi}-\mathrm{Cr}$ steel roll was better than that of the $\mathrm{Hi}-\mathrm{Cr}$ iron roll due to the 
influence of the hardness on wear as described.

The average performance of the $\mathrm{Hi}-\mathrm{Cr}$ steel roll on secondary stands of the roughing mills was from 60000 to $80000 \mathrm{t} / \mathrm{mm}$ (the weight of rolled products per unit diameter loss of a roll), where that of the $\mathrm{Hi}-\mathrm{Cr}$ iron roll was from 40000 to $60000 \mathrm{t} / \mathrm{mm}$.

\section{Conclusion}

The results can be summarized as follows:

(1) The secondary dendrite arm spacing of $\mathrm{Hi}-\mathrm{Cr}$ steel is larger than that of $\mathrm{Hi}-\mathrm{Cr}$ iron, and inversely proportional to parameter $L$, the fraction of eutectic.

(2) The wear of the $\mathrm{Hi}-\mathrm{Cr}$ iron and steel depends on the wear mechanism. The governing factor is hardness for mechanical abrasion, and the volume fraction of carbide for abrasion with melting.

(3) The thermal shock resistance is affected by the chromium content in $\mathrm{Hi}-\mathrm{Cr}$ iron and steel materials. A chromium content above $10 \%$ is suggested for a $\mathrm{Hi}-\mathrm{Cr}$ steel roll.

(4) Using the $\mathrm{Hi}-\mathrm{Cr}$ steel roll instead of the $\mathrm{Hi}-\mathrm{Cr}$ iron roll in the roughing at a hot strip mill, the roughness of roll surface became large. Then accidental slippage was prevented and the performance was imporved with increasing hardness.

\section{REFERENCES}

1) J. Werquin and J. Bocquet: Bull. Cercle Étud. Métaux, 15 (1978) $5,28.1$.

2) D. J. Tarney and J. C. Wequin: Work. Steel Process., 21 (1984), 181.

3) J. C. Werquin and J. C. Caillaud: Mech. Work. Steel Process., 25 (1988), 311.

4) I. Sadler and T. P. Adams: Mech. Work. Steel Process., 25 (1988), 295.

5) M. Spindel: VDI, 70 (1926), 415 .

6) K. Sakabe and H. Tabe: Tetsu-to-Hagané, 57 (1971), 5, 836.

7) F. Maratray, A. Poulalion and P. Rabbe: Bull. Cercle Étud. Métaux, (1973), 11 